University of Wollongong

Research Online

Faculty of Business - Papers (Archive)

Faculty of Business and Law

$1-1-2014$

The effect of chronic pain on life satisfaction: evidence from Australian data

Paul Mcnamee

University of Aberdeen

Silvia Mendolia

University of Wollongong, smendoli@uow.edu.au

Follow this and additional works at: https://ro.uow.edu.au/buspapers

Part of the Business Commons

Research Online is the open access institutional repository for the University of Wollongong. For further information contact the UOW Library: research-pubs@uow.edu.au 


\title{
The effect of chronic pain on life satisfaction: evidence from Australian data
}

\begin{abstract}
Chronic pain is associated with significant costs to individuals directly affected by this condition, their families, the healthcare system, and the society as a whole. This paper investigates the relationship between chronic pain and life satisfaction using a sample of around 90,000 observations from the first ten waves of the Household, Income and Labour Dynamics of Australia Survey (HILDA), which is a representative survey of the Australian population that started in 2000 . We estimate the negative impact on life satisfaction and examine the persistence of the effect over multiple years. Chronic pain is associated with poor health conditions, disability, decreased participation in the labour market and lower quality of life. We calculate the compensating income variation of chronic pain, based on the measurement of chronic pain, the life satisfaction of individuals and the income of households. Panel data models with random and fixed effects are used to control for characteristics of individuals that do not vary over time. Further, we investigate whether individuals who experience chronic pain exhibit adaptation and recovery in life satisfaction after 3 years. Overall, we find that chronic pain has a large negative association with life satisfaction and that the compensating income variation is substantial (around US\$ 640 per day).
\end{abstract}

\section{Keywords}

satisfaction, life, pain, chronic, effect, evidence, australian, data

Disciplines

Business

\section{Publication Details}

Mcnamee, P. \& Mendolia, S. (2014). The effect of chronic pain on life satisfaction: evidence from Australian data. Social Science and Medicine, 121, 65-73. 


\title{
The effect of chronic pain on life satisfaction: evidence from Australian data
}

\begin{abstract}
:
Chronic pain is associated with significant costs to individuals directly affected by this condition, their families, the healthcare system, and the society as a whole. This paper investigates the relationship between chronic pain and life satisfaction using a sample of around 90,000 observations from the first ten waves of the Household, Income and Labour Dynamics of Australia Survey (HILDA), which is a representative survey of the Australian population that started in 2000. We estimate the negative impact on life satisfaction and examine the persistence of the effect over multiple years. Chronic pain is associated with poor health conditions, disability, decreased participation in the labour market and lower quality of life. We calculate the compensating income variation of chronic pain, based on the measurement of chronic pain, the life satisfaction of individuals and the income of households. Panel data models with random and fixed effects are used to control for characteristics of individuals that do not vary over time. Further, we investigate whether individuals who experience chronic pain exhibit adaptation and recovery in life satisfaction after 3 years. Overall, we find that chronic pain has a large negative association with life satisfaction and that the compensating income variation is substantial (around US\$ 640 per day).
\end{abstract}

Keywords: Australia, Chronic Pain, Life Satisfaction; Compensating Income Variation; Adaptation; Fixed effects 


\section{Introduction}

Evaluation of the worth of new and existing health care interventions requires some knowledge regarding individuals' evaluations of their health improvements. Cost-effectiveness and cost-utility analyses help to compare different types of interventions in terms of their effectiveness and health-related quality of life but provide only limited information on the contribution to individuals' overall welfare.

One way to assess the welfare changes associated with health improvements is to analyse individuals' willingness to pay for specific interventions. However, there are difficulties in quantifying health-related benefits with this kind of methodology (Labelle and Hurley, 1992). In particular, existing methods for calculating willingness to pay are based on preference measurement, which can be done by observing individual behaviour and deducing preferences (revealed preferences) or by directly asking individuals to state their preferences (hypothetical preferences) (see for example Chuck et al., 2009). However, both methods have their limitations, either because of potential sample selection (Heckman, 1979), or because individuals are asked to consider hypothetical situations of which they have no personal experience, which can mean responses may be subject to a variety of biases (Groot and Maassen van den Brink, 2004).

To overcome some of these limitations, a different methodology, compensating income variation (CIV), has been developed and applied in the literature to value some of the consequences of a variety of health- problems, such as migraine (Groot and Maassen van den Brink, 2004), cardio-vascular disease (Groot and Maassen van den Brink, 2006), chronic disease (Ferrer-I-Carbonell and van Praag, 2002), informal care (Mentzakis et al, 2012), and disability (Oswald and Powdthavee, 2008), as well as to evaluate the effects of other major life events (see for example Clark and Oswald, 2002, Van Praag and Ferrer-I-Carbonell, 2004, Groot and Maassen van den Brink, 2007, and Carroll et al., 2009). 
One of the potential uses of CIV is that, through estimation of monetary values for health states, direct comparison of the relative benefits and costs of alternative health care treatments or interventions in monetary terms becomes possible. Whilst it is recognised that, within health care, such comparison is often undertaken using estimates of cost per QALY in cost utility analysis, in some instances (e.g. where the cost per QALY value is highly uncertain, or covers a range that makes policy recommendations more challenging) an indication of the monetary value of a health condition may provide decision-makers with additional information to help inform a policy recommendation. More widely however, there may be concern that the benefits from some health care interventions, when measured in terms of "natural units" such as cure rates or valued using QALYs, may be undercounted in situations where health care treatments affect wider aspects of a person's life.

In the health applications, individual life satisfaction is estimated as a function of various individual characteristics, such as household income, health and other factors affecting welfare, such as marital status and education. The results from the estimation are used to calculate an income-health trade off, keeping life satisfaction constant. This trade off, or compensating income variation, represents the monetary compensation needed by an individual with a particular health problem to have the same level of life satisfaction of an individual without the same health problem. Whilst the literature in this field suggests that it is feasible to produce valuations, a question remains however over the validity of the estimates generated. In particular, estimates can be unstable when different model specifications are used (Groot and Maassen van den Brink, 2004). Moreover, a somewhat neglected feature of the existing studies is that they make little attempt to capture explicitly the influence of health dynamics, such as adaptation. This is important as life satisfaction levels for people with chronic conditions might be expected to change over time due to a re-framing of the problem, that is, over time, people adapt to their condition (a phenomenon also called 'habituation' or 'response shift' (Galenkamp et al., 2012). Also, it is possible that different people exhibit different tendencies to adapt to 
changes in health, for example, the response to chronic disease may differ between men and women, as demonstrated by Hasmi and Davis (2009), who find that women demonstrate more adaptation to some forms of pain. More generally, much work in psychology shows that happiness levels bounce back after a negative life shock (Oswald and Powdthavee, 2008), although Easterlin (2005) observes that there are different levels of habituation across different domains in life, with more adaptation found in pecuniary rather than non-pecuniary domains.

In the health context, if adaptation is present and leads to additional changes in life satisfaction over and above those that can be attributed to changes in health, and if such adaptation is more prevalent in particular population groups, then knowledge of the magnitude of the effect is important in the generation of estimates of compensating income variation.

We address these issues by considering the condition of chronic pain. This is defined as "pain that persists past the normal time of healing" (Merskey \& Bogduk, 1994, p. xi) or as pain that has lasted longer than three to six months (Debono et al., 2013). Chronic pain is considered here as it is associated with large increased health care costs, productivity costs and negative welfare consequences for the individual, their family and society as a whole (Philips, 2009; Christensen et al., 2011; and Philips and Harper, 2011). Costs are large in part because many people are affected, for example, the Institute of Medicine of the National Academies Report (2011) indicates that chronic pain affects around one-half of all adult Americans, whilst in Australia, it is suggested that approximately $30 \%$ of Australians are affected (Pfitzer Health report, 2011). For Australia, the total cost of pain is estimated at A $\$ 34.2$ (US\$30) billion in 2007, or A \$10,847 (US\$9,546) for each person with chronic pain (Access Economics, 2007). Productivity costs form the largest share of total costs, with pain playing a central role in individuals' dynamics of employment and being a key determinant of self-reported work disability (Kapteyn et al., 2008). People with persistent pain are more than twice as likely to 
have difficulty working (Schofield et al., 2012) or to lose hours of productive time at work (Stewart et al., 2003).

Chronic pain is also well-suited to examine the influence of adaptation on life satisfaction in general and measures of compensating income variation in particular. Measures of subjective well-being such as questions on life satisfaction have been widely used in social sciences and psychology, as well as in some economic studies (see for example Clark and Oswald, 1994; Frey and Stulzer, 2000; Winkelman, 2005). A problem with these measures is that individuals' responses to these questions are related to individual personality characteristics that are unobserved or unmeasured, and this may lead different individuals to attach a different meaning to the definition of terms such as "totally satisfied with your life". This is compounded by a condition such as chronic pain, where adaptation to the condition is possible. Indeed, the bedrock of "treatment" in chronic pain is the development of self-management approaches, many of which are based on cognitive behavioural therapy (CBT). Such therapeutic approaches encourage adaptation through the development of positive thoughts, feelings and attitudes towards adverse circumstances.

The objective of this paper therefore is to analyse the relationship between chronic pain and life satisfaction of adult individuals, using data from the Household, Income and Labour Dynamics in Australia (HILDA) Survey. We examine whether the impact of chronic pain on life satisfaction is lessened over time through adaptation, and assess the consequences of adaptation for estimates of compensating variation.

The rest of this paper is organized as follows. Section 2 describes the data and briefly presents pain and well-being indicators. Section 3 discusses the estimation methods and Section 4 presents the main results. Section 5 concludes. 


\section{Data}

This paper uses data from ten waves of the HILDA Survey, which is a representative longitudinal study of the Australian population that started in 2000. A total of 13,969 individuals in 7,682 households were interviewed in wave 1 through a combination of face-to-face interviews and self-completion questionnaires, for all members of households aged 15 years old and over (Wooden and Watson, 2002). HILDA is an indefinite life panel survey with a strong focus on family formation, income and work. All members of the households interviewed in wave 1 form the basis of the sample and they were interviewed in each subsequent wave. The sample has then been extended and now includes any new household members resulting from changes in the composition of the original households. In this study, we conduct secondary analysis on a non-identifiable dataset and therefore did not need to seek ethics approval. HILDA includes two different measures of pain. First, starting at wave 3, at each wave, individuals are asked whether they have any long term health conditions, with chronic pain as one of the possible alternatives that can be selected. Second, respondents are asked about the amount of bodily pain they had in the last 4 weeks and they can select one of the following alternatives: no pain at all; very mild; mild; moderate; severe; very severe. The focus of our paper is on chronic pain and therefore we decided to use the first indicator as our main variable of interest. Sensitivity tests have been run using the responses about bodily pain in the last 4 weeks and results are very similar.

Respondents are asked to report their life satisfaction at each wave in HILDA. They answer the following question: How satisfied are you with your life? and answers are on a scale from 0 (totally dissatisfied) to 10 (totally satisfied). Life satisfaction has been defined as 'a feeling of contentment and lack of dissatisfaction with all areas of one's life' (Ardelt 1997, p. 16-17), and is commonly used as a measure of well-being (Mentzakis et al. 2012; Veenhoven 2007; Diener 
and Suh 1997). The question on life satisfaction is asked towards the end of the HILDA survey and is quite far from the questions on recurring health conditions and chronic pain.

Further, we use an extensive set of control variables, to account for other factors that may influence life satisfaction. In the first specification of the model we only include chronic pain and logarithm of household income. In the second specification, we also control for health limitations (other long term conditions), and in the third specification we include a wider set of independent variables. These include: a set of life events that took place in the last 12 months (personal injury or illness, victim of physical violence, other shocks, such as death of a family member, friend, or victim of a property crime) and a number of socio-demographic characteristics, such as age, education, marital status, living arrangements, smoking status, presence and age of children, employment status, geographic remoteness (we follow Frijiters et al., 2004 and do not control simultaneously for age, time and fixed-effects. We therefore drop age as a covariate and note that the time dummies will include age effects.). The complete list of variables included in our model is reported in Table 1. Our final sample includes around 90,000 observations of around 17,800 individuals with non-missing information on chronic pain, health conditions and other essential information on the individual and family characteristics (the selected observations were not significantly different from the original data in terms of their observable characteristics). These individuals have developed chronic pain at various points in time, both before and after the beginning of the survey. However, we tested our model on a subsample of individuals developing chronic pain after the beginning of the survey and main results are unchanged.

Table 2 presents the distribution of pain and life satisfaction across the estimation sample. The percentage of individuals with low life satisfaction is generally quite low in the estimation sample (around 2.5\%) but increases substantially when we separately look at the people affected 
by chronic pain $(9 \%)$. In the estimation sample, around $6 \%$ of individuals (more than 5,000 observations) have pain.

\section{Table 1 here}

\section{Table 2 here}

Table 3 presents descriptive statistics on the other independent variables included in our model, by chronic pain status. Individuals with chronic pain are more likely to be out of the labour force, have lower education and income, and are generally affected by various chronic health conditions, especially motor impairments (limited use of arms, feet or legs, difficulty gripping things, any condition that restricts physical activity), long term health conditions (arthritis, asthma, heart disease, Alzheimer's disease, dementia etc.) and other conditions (loss of consciousness, learning difficulties, shortness of breath, results of a head injury).

\section{Table 3 here}

\section{Estimation}

Our model builds upon previous literature (Groot and Maassen van den Brink, 2004 and 2006, Carroll et al. 2009), and we assume an underlying indirect life satisfaction function (LS*). We assume that life satisfaction (measured on a 0-10 scale) is influenced by income $\mathrm{Y}$, health status $\mathrm{H}$ and other individual characteristics $\mathrm{X}$ :

$$
\mathrm{LS}^{*}=\mathrm{LS}^{*}[\mathrm{Y}, \mathrm{H}, \mathrm{X}]
$$

The major challenge for such analyses is that of establishing causal connections between chronic pain and life satisfaction, given that people with chronic pain may have unobserved characteristics that also affect their life satisfaction and other outcomes. Furthermore, people with chronic pain may be systematically different from those who have no experience of chronic pain, and reporting of chronic pain might be affected by individuals' overall perceptions of their own lives and therefore by their own life satisfaction. If these conditions hold, then linear 
regression analysis using Ordinary Least Squares (OLS) methods will generate results that may be best regarded as upper bound estimates of the effects. We cannot, in these data, address the selection on unobservables problem. There is simply no quasi-experimental variation across our sample to exploit. Further, detecting an instrumental variable that is correlated with chronic pain but uncorrelated with the error terms in the life satisfaction equation seems highly problematic, if not impossible. Recent literature using instrumental variables in the context of health conditions has shown how complicated it is to identify potential instruments for health conditions (see for example Dee, 1999, using within-state variation in cigarettes taxes as an instrument for smoking; Almond, 2006, who uses variation in the prevalence of influenza in the US during the flu pandemic of 1918 as an instrument for in utero environment of those born shortly thereafter; Rees and Sabia, 2011, who use maternal migraine history as an instrument for individual migraine; and Cawley and Meyeroefer, 2012, using genetic variation in weight as an instrument for obesity). In our data, there is no suitable instrument to utilise to create exogenous variation in chronic pain status and therefore we decided not to use this technique. Further, instrumental variable estimation is not a panacea and the risks of choosing an invalid instrument or one that is weakly correlated with the endogenous regressor are very high, as such instruments will lead to inconsistent and biased estimates. (see Murray, 2006 for a discussion). We try therefore to minimise the potential upward bias of the OLS estimates by adopting three strategies.

First, we examined the impact of prior versus current chronic pain by estimating models using chronic pain at $\mathrm{t}$ and also at $\mathrm{t}-1$ and found that the results were very similar. For reasons of interpretability and comparison with prior studies, we only show results from the estimation with chronic pain at time $\mathrm{t}(\mathrm{t}-1$ estimates are available on request). Second, we try to lower the upper bound by examining the effect of the inclusion of additional independent variables (controls for age, health status, and a range of other characteristics and negative life events 
(such as being the victim of violence, property crime, death or serious illness of a family member or close friend, etc.). Lastly, to account for individual unobserved traits and characteristics that do not vary over time, we employ fixed effects estimation. That is, life satisfaction is assumed to be a linear function of health conditions other than chronic pain, $H_{i t}$, income, $Y_{i t}$, chronic pain $P_{i t}$, and other individual characteristics $X_{i t}$ :

$$
L S_{i t}=\alpha+\beta_{1} H_{i t}+\beta_{2} \log Y_{i t}+\beta_{3} X_{i t}+\beta_{4} P_{i t}+\varepsilon_{i t}+c_{i}
$$

Where $\varepsilon_{i t}$ is an idiosyncratic individual error term, which is assumed to be normally distributed (with variance normalised to be equal to 1) and $c_{i}$ is an individual fixed effect that takes into account time-invariant unobserved heterogeneity. The variance of the idiosyncratic error term is normalised to be equal to 1 .

Equation 2 is estimated using linear Ordinary Least Squares (OLS) and Ordered Logit models, and then extended using individual random and fixed effects models, to show the stability of our main results. Therefore we take into account individual-specific factors such as personality (see Cobb-Clark and Schurer, 2012 on the stability of personality traits.), cultural background, etc. that do not vary over time. These factors may affect the perception of life satisfaction, as well as reporting of chronic pain, which may also be a function of the degree of pain experienced in the past. For example, if a person is intrinsically pessimistic and tends to over-report chronic conditions, the fixed effects estimator should take this into account.

Estimation of a model with individual fixed effects allows us to relax the assumption (which is required when estimating a model with individual random effects) that $\mathrm{E}$ (cilXi) $=0$. This means that some of the regressors may be endogenous but endogeneity is modelled as a dependence of the regressors with an unobserved component that is fixed over time. Since it does not rely on the orthogonality of ci with respect to $\mathrm{Xi}$, the fixed effects estimator is more robust than the random effects. 
However, the causal interpretation of results relies on the assumption that the timedependent error term in our model is independent of chronic pain, conditional on the regressors included in the model and on the individual fixed effect. This assumption will not hold if there are unobserved random shocks that affect chronic pain and life satisfaction. For this reason, we control for health conditions, as well as for other negative life events (such as being the victim of violence, property crime, death or serious illness of a family member or close friend, etc.). We also test our main results by using a model where the dependent variable is collapsed into a binary format and the correction proposed by Ferrer-I-Carbonell and Frijters (2004) which applies an individual specific threshold to collapse the data into a binary format. Results are not presented for reasons of parsimony but are very similar to the ones presented and are available on request.

An alternative to the fixed effects estimator is the Anderson Hsiao first difference method, which relies on taking first differences over time for all variables in the model and estimating the same model on differences rather than levels. Unfortunately, this model still relies on the strict exogeneity assumption that $\mathrm{E}\left(\varepsilon_{\mathrm{it}} \mid \mathrm{X}_{\mathrm{i}}\right)=0$ and if this assumption is violated the estimator will not be consistent (Wooldridge, 2002). The fixed effects estimator is more efficient if the error terms are serially uncorrelated, while the first difference estimator is preferred if the error follows a random walk. As Wooldridge (2002) notes, in many cases the truth is likely to be in between these two options, so the two estimators will produce similar results and will have similar caveats.

We use the parameter estimates from (2) to calculate the CIV of chronic pain, i.e. the amount of money needed to compensate someone affected by chronic pain and make her/him as well-off as someone without pain. As noted in Powdthavee (2005), as our equivalised income variable is expressed in terms of logarithm income, the compensating income variation (CIV) equation can be written as: 


$$
C I V=\left[\exp \left(\operatorname{abs} \frac{\beta_{4}}{\beta_{2}}\right)-1\right] * Y
$$

To examine adaptation, we follow Oswald and Powdthavee (2008) and consider chronic pain in current and prior waves to assess whether life satisfaction levels adapt, by creating a variable "Past chronic pain from t-3 to t-1", $P_{i t-3}$, which takes values between zero and unity. An individual who had chronic pain for one previous year in the last three years, for example, will have the value $1 / 3$ for his or her past chronic pain from $t-3$ to $t-1$. More specifically, the variable $P_{i t-3}$, will be equal to:

- $1 / 3$ if the respondent experienced chronic pain in one out of three years

- $2 / 3$ if the respondent experienced chronic pain in two out of three years

- 1 if the respondent experienced chronic pain every year

This is introduced into the model separately and interacted with current chronic pain $P_{i t}$ :

$L S_{i t}=\alpha+\beta_{1} H_{i t}+\beta_{2} \log Y_{i t}+\beta_{3} X_{i t}+\beta_{4} P_{i t}+\beta_{5} P_{i t-3}+\beta_{6 t}\left(P_{i t} * P_{i t-3}\right)+\varepsilon_{i t}+c_{i}$

The estimation of the model from equation 4 allows us to test whether past chronic pain reduces life satisfaction for those who have recovered from it and whether the effect of current chronic pain is smaller for individuals who have experienced this condition for a longer time in the past.

\section{Results}

The main results from our model are presented in Table 4-6. We present results for the whole estimation sample, as well as for men and women separately. In order to show the stability of our results, we present results from three different specifications of the OLS model, where additional independent variables are included, an Ordered Logit model (in order to take into account that life satisfaction is measured on a scale 0-10), as well as OLS with random and fixed effects. 
First of all, we progressively increase our set of independent variables in the OLS estimation, in order to capture factors that could be correlated with chronic pain, such as long term health conditions and life events. Second, there might be unobserved time invariant factors correlated both with chronic pain and life satisfaction. If this is the case, the random effects estimator will be inconsistent. Accordingly, in Table 4 we also present fixed effects panel estimates, which are consistent under the assumption that there are no omitted time-varying factors that are also correlated with the chronic pain variable. As expected, the point estimates from fixed effects are lower than in the OLS and random effects model. We performed a Hausman test and this showed that the hypothesis that the difference in coefficients is not systematic could be rejected and therefore the fixed effects estimates are preferred (Chi-squared statistics $=522.16$ and $\mathrm{p}$-value $=0.000)$.

Chronic pain has a large, negative and significant association with life satisfaction for people in our sample. As expected, the size of the coefficient decreases when we add more independent variables and individual fixed effects. However, the coefficient of chronic pain is still significantly different from zero in the preferred fixed effects specification. Chronic pain appears to have a slightly stronger negative relationship with men's life satisfaction: for a 45 year old man (approximately the average age of the individuals in our sample), chronic pain reduces life satisfaction by around 0.10 points on a $0-10$ scale. For a woman of similar age the effect is 0.08 points on a $0-10$ scale.

\section{Table 4 and 5 here}

Our results also show a small, positive association between income and life satisfaction and this is consistent with previous studies using the compensating income variation approach (Mentzakis et al. 2012; Groot and Maassen van den Brink 2004 and 2006).

The independent variables included in the model follow other studies of life satisfaction (see for example Blanchflower and Oswald, 2008; Wooden et al., 2009, Green, 2011) and the main findings on these variables are generally consistent with previous literature investigating 
the determinants of life satisfaction (see for example Winkelmann and Winkelmann 1998, Clark et al. 2001; Frey and Stutzer 2000; Frijters et al. 2004). Life satisfaction is negatively affected by long term health conditions, while education does not seem to play a very important role in our sample. Labour force participation definitively increases life satisfaction, with respect to unemployment. Married individuals generally exhibit higher levels of life satisfaction, while negative life events, such as personal injury, illness or death of a family member or close friend and being a victim of violence, have a strong negative effect on individual life satisfaction. People living in a rental property are less satisfied than people who own their house, while people living in inner regional areas seem more satisfied than people living in major cities. The negative effects of being unemployed, separated or widowed on life satisfaction are stronger for men, while women's life satisfaction is negatively affected by the presence of very young children.

\section{Table 6 here}

The compensating income variation associated with chronic pain for the complete sample is estimated as AUS\$730 per day (around US\$640). Compared to an individual without chronic pain with an average equivalised daily disposable income of approximately AUS\$81 (US\$71), an individual with chronic pain needs an extra AUS\$730 (US\$640) to achieve the same level of life satisfaction.

Lastly, we estimate equation 4 and investigate whether people with chronic pain at the present time $\mathrm{t}$ and in prior time periods exhibit adaptation to their condition and whether there is a difference in adaptation between men and women. Results from the estimation are reported in Table 7.

\section{Table 7 here}

The long-run effect of chronic pain is 0.17 (equal to the sum of -0.094 and -0.078 ) for the whole sample, 0.10 (sum of -0.078 and -0.019 ) for women and 0.27 (sum of -0.113 and -0.162 ) 
for men. In the second column of Table 7, we include the coefficient of past chronic pain, as well as the interaction between past and current pain. The inclusion of these variables allows us to estimate the extent of adaptation. For example, a person who had chronic pain for every year in the last three years has a ratio of time in chronic pain from $\mathrm{t}-3$ to $\mathrm{t}-1$ equal to 1 . Hence, other factors held constant, the effect on life satisfaction is (-0.195). In addition, if this individual also reports chronic pain at time $t$, there is an offsetting effect, captured by the interaction term and the overall effect is equal to $-0.143-0.195+0.229=-0.109$. This coefficient is smaller than -0.143 (the effect of contemporaneous chronic pain) and shows a partial adaptation of about $24 \%$. A person who had chronic pain for one additional year in the past has a combined penalty of $0.143-0.195 / 3+0.229 / 3=-0.132$. A person who had chronic pain for two additional years in the last three would have a life satisfaction penalty of $-0.143-2 / 3(0.195)+2 / 3(0.229)=-0.120$. These data show that the negative effect of chronic pain on life satisfaction slightly fades when people experience the condition for a more prolonged period of time. Oswald and Powdthavee (2008) analyse adaptation to disability and severe disability (limiting day-to-day activities) and show that individuals' life satisfaction adapt to a larger extent to the first type of condition (the longer the experience of disability, the less emotionally painful current disability appears to be) but not so much to the most severe disability: three full years of this type of disability produces only mild happiness adaptation. Finally, note that a person with no chronic pain today but with a history of chronic pain in one of the three previous waves still experiences a penalty of $0.195 / 3=-0.065$

Interestingly, women seem to react to chronic pain better than men. The effects reported above are -0.10 (1 year), -0.066 ( 2 years) and -0.032 (3 years) for women, while the effect of contemporaneous chronic pain on life satisfaction is -0.133 . Therefore women who had chronic pain constantly for the last 3 years show more than $70 \%$ adaptation. On the other hand, the effects for men are -0.174 ( 1 year), -0.20 (2 years), and -0.22 (3 years) for men, and the effect of 
contemporaneous pain is -0.151 , showing no adaptation at all (and an actual worsening of life satisfaction) for men.

We further explore the effect of the duration of chronic pain by estimating a different model including a variable denoting how long the respondent has been suffering for chronic pain since the beginning of the survey (with values from 1 to 8 years) and another variable denoting the duration squared. We then estimate the effect of these variables on the subsample of individuals affected by chronic pain. Results are reported in Table 8 and are generally consistent with findings presented in Table 7. Prolonged exposure to chronic pain seems particularly detrimental for men's life satisfaction, with a U shaped effect signaling that the strongest negative effect on life satisfaction is experienced after around 4 years of chronic pain. Information on the starting date of chronic pain was also collected in HILDA after wave 4, but unfortunately only $40 \%$ of respondents with chronic pain reported a starting date (with dates between 1917 and 2010). We have used this information in a sensitivity test, but the overall duration of chronic pain does not seem to affect life satisfaction. However, this result could have been affected by the limited sample (only 2,500 observations) and the dispersion of the data on durations (from 0 to 88 years). The CIV values are sensitive to the incorporation of adaptation. For example, rather than the average value of 730 AU\$ across the entire sample, from Table 7, the coefficient values suggest that a person with chronic pain at time $t$ and three previous years of chronic pain would need an extra AU\$1,244 [exp abs(-0.109/0.039)-1]* 81. Beyond three years, the values from Table 8 suggest further reduction in CIV values. However, given the limited number of observations for longer durations of chronic pain, there is considerable uncertainty regarding the longer term impacts of adaptation.

\section{Table 8 here}

\section{Discussion}

This paper analyses the relationship between chronic pain and life satisfaction, using the Household, Income and Labour Dynamics Survey of Australia. Fixed effects have been used in 
the present analysis to control for characteristics of individuals that do not vary over time. To the best of our knowledge, this is the first study to consider the application of the compensating income variation method to chronic pain, as well as explore the impact of differential adaptation between men and women on the resulting estimates. We find that chronic pain has a large negative effect on life satisfaction and that the compensating income variation is substantial (around US\$640 per day). Amongst men, the negative effect on life satisfaction is persistent and individuals with chronic pain do not show significant adaptation. Some adaptation is observed however amongst women.

The negative association between chronic pain and life satisfaction is not entirely unexpected if one considers the various transmission channels through which chronic pain can affect individual well-being. First of all, many forms of chronic pain cannot be effectively treated by standard medical care, and treatment is mostly focused on delivery of selfmanagement strategies (Martin et al 2013), but their effectiveness is uncertain (Boyers et al 2013) and uptake is variable (Schofield et al 2012). Second, chronic pain has been found to increase the chances of leaving the labour market and this may imply a drop in income, as well as a negative effect on individual perceived role in society. Even if we control for income and employment status in our model, the negative effect of chronic pain may go through a variety of other factors, such as individual perception of her/his own role, self-esteem, lack of personal contacts, etc. Lastly, chronic pain may increase individual stress and therefore increase the chances of family conflicts, and other problems in individual relationships. Taken together therefore, it suggests a need for development of effective chronic pain prevention strategies, as well as better chronic pain management, through encouragement of self-management approaches which teach adaptation.

Men seem particularly affected by the incidence of pain, and less able to adapt to it over time. Women show some adaptation when they experience chronic pain for a prolonged period of time. The explanation for the difference between men and women may arise as the effect of 
chronic pain on individual life satisfaction can be mediated through a variety of different factors. Whilst the persistent experience of pain, and the associated difficulty in finding an appropriate treatment, are likely to worsen psychological well-being for both, as already shown in previous studies, chronic pain has severe negative adverse consequences on individual labour market participation and productivity. Literature from health sciences has shown that women experience higher pain incidence but generally show less pain-related anxiety (Frot et al., 2004) and greater adaptation (Hashmi and Davis, 2009). Further, chronic pain may have a different effect for women as opposed to men through the labour market consequences, due to social norms, self-esteem and perceived role in society. Whilst prolonged experience of pain may inhibit social interactions, personal relationships, and levels of stress, self-management can be used to help ameliorate these consequences, and it may be that men and women exercise different choices over the extent to which they engage in self-management strategies. Women have been found to be more proactive in managing chronic diseases and integrating self-care into their daily life (Mathew et al., 2012). The potential explanations for the differences are many and complex, and we leave that as a challenge for future research. A possible limitation of our analysis is that the fixed effects estimates only control for time-invariant effects, and it is possible that other time-varying variables affect both chronic pain and life satisfaction, or that reverse causality affects the main results. However, it is difficult to adopt analytical solutions to these problems as there is no quasi-experimental variation that could be used to deal with these issues. Furthermore, there is a lack of suitable instrumental variables with the power to predict chronic pain without having an effect on individuals' life satisfaction. Therefore, we interpret our results as strong associations between chronic pain and life satisfaction, rather than definitively stating that the process is causal.

Another limitation of the analysis is that compensating income variation only captures the implied monetary compensation that would allow an individual with chronic pain to achieve the same level of life satisfaction as an individual without chronic pain. However, this could be a 
temporary or partial compensation in life satisfaction, as there are many knock-on effects of this kind of health limitation that could continue to be affected or even worsened, such as, for example, changes in social relationships. Further, people are likely to adapt more quickly to an increase in their income than they will adapt to their long term health condition.

The implied average compensation value is higher than some previous estimates of other chronic conditions, e.g. Groot and Maassen van den Brink (2004 and 2006) estimate CIV for migraine of US\$1,400 per month (1993 prices) and $£ 4,000$ per month for cardiovascular disease amongst males (1996-2000 prices). However, other authors demonstrate more comparable figures to ours, e.g. Clark \& Oswald (2002) find that a shift from excellent to fair health implies a valuation of $£ 41,000$ per month (1992 prices). The reasons for these differences in magnitude are unclear, as different data sources, health conditions and estimation models have been utilized. Further work using additional data, to exploit exogenous random variation in chronic pain and household income, would permit greater insight into the validity of our estimates and those of previous authors. Whilst valuations could be used in preliminary studies that are estimating the value for money of chronic pain prevention or management programs, and are considering whether the extra costs are outweighed by the benefits in terms of cases of chronic pain prevented or cured, at the present time we urge caution in the interpretation of our results and any comparison with other studies. 


\section{Tables}

Table 1 - Independent variables

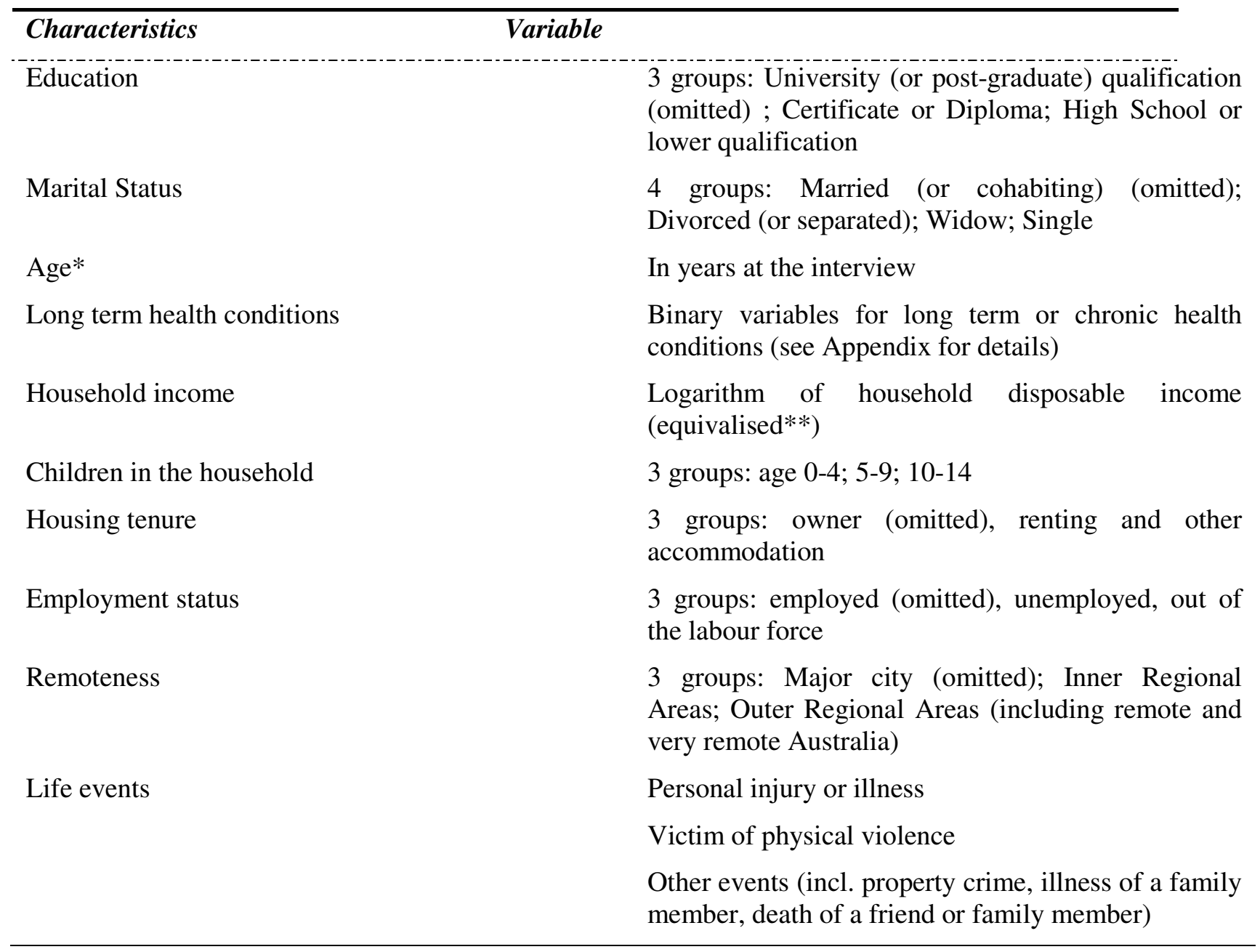

\footnotetext{
**Not included in the Fixed effects model
}

**Equivalised income has been calculated using the modified OECD scale: weights of 1 for the first adult, 0.5 for subsequent adults age 14 and over- and 0.3 for each child. See Clark et al.(2005) for further explanations 
Table 2 - Distribution of chronic pain and life satisfaction

\begin{tabular}{|c|c|c|c|}
\hline \multicolumn{2}{|c|}{ Overall life satisfaction levels } & Frequency & Percent \\
\hline Least satisfi & $-4)$ & 2,133 & 2 \\
\hline 5 & & 3,484 & 4 \\
\hline Satisfied & & 84,525 & 94 \\
\hline \multicolumn{4}{|c|}{ Chronic pain } \\
\hline No & \multicolumn{2}{|r|}{84,821} & 94 \\
\hline \multirow[t]{2}{*}{ Yes } & \multicolumn{2}{|r|}{5,321} & 6 \\
\hline & \multicolumn{3}{|c|}{ Life satisfaction (\%) } \\
\hline Pain & Least Satisfied (0-4) & 5 & Satisfied (6-10) \\
\hline No chronic pain & 2 & 4 & 94 \\
\hline Chronic pain & 9 & 10 & 81 \\
\hline
\end{tabular}

Note: The sample is that used for the analyses with fixed effects in Table 4 below, with 90,142 person-year observations. The means are unweighted. 
Table 3: Descriptive statistics of independent variables

\begin{tabular}{|c|c|c|c|c|}
\hline Variable & All & No chronic pain & Chronic pain & $\begin{array}{l}\text { Difference in } \\
\text { means }(\mathrm{p}-\end{array}$ \\
\hline Equivalised yearly income (Mean- SD) & $38,201(25,794)$ & $38,735(25,936)$ & $29,689(21,716)$ & 0.000 \\
\hline \multicolumn{5}{|l|}{ Marital Status (\%) } \\
\hline Single & 21 & 24 & 11 & 0.000 \\
\hline Separated/Divorced & 9 & 8 & 16 & 0.000 \\
\hline Married Or Cohabiting & 63 & 63 & 62 & 0.000 \\
\hline Widow & 5 & 5 & 10 & 0.000 \\
\hline \multicolumn{5}{|l|}{ Employment Status (\%) } \\
\hline Employed & 65 & 67 & 32 & 0.000 \\
\hline Unemployed & 3 & 2 & 3 & 0.000 \\
\hline Out of the $\mathrm{L}$ force & 32 & 30 & 65 & 0.000 \\
\hline \multicolumn{5}{|l|}{ Housing tenure (\%) } \\
\hline Owned & 72 & 72 & 67 & 0.000 \\
\hline Rented & 25 & 25 & 28 & 0.000 \\
\hline Other living arrangements & 3 & 3 & 4 & 0.000 \\
\hline \multicolumn{5}{|l|}{ Educational Qualification (\%) } \\
\hline University (or post grad.) qualification & 21 & 22 & 15 & 0.000 \\
\hline Certificate or Diploma & 30 & 30 & 30 & 0.801 \\
\hline High School or Lower Education & 48 & 48 & 54 & 0.000 \\
\hline \multicolumn{5}{|l|}{ Remoteness (\%) } \\
\hline City & 61 & 62 & 57 & 0.000 \\
\hline Inner regional area & 25 & 24 & 28 & 0.000 \\
\hline Outer regional area & 13 & 13 & 14 & 0.013 \\
\hline Age (Mean - SD) & $45(17.9)$ & $43(18.01)$ & $56(15.8)$ & 0.000 \\
\hline Male $(\%)$ & 47 & 47 & 42 & 0.000 \\
\hline Children 0-4 (\%) & 14 & 14 & 6 & 0.000 \\
\hline Children 5-9 (\%) & 13 & 14 & 8 & 0.000 \\
\hline Children 10-14 (\%) & 17 & 17 & 10 & 0.000 \\
\hline \multicolumn{5}{|l|}{ Life events (\%) } \\
\hline Personal illness or injury & 8 & 8 & 26 & 0.000 \\
\hline Victim of violence & 1 & 1 & 2 & 0.000 \\
\hline Other life events & 34 & 33 & 44 & 0.000 \\
\hline \multicolumn{5}{|l|}{ Health conditions (\%) } \\
\hline Sensory problems & 7 & 6 & 26 & 0.000 \\
\hline Motor impairments & 6 & 4 & 42 & 0.000 \\
\hline Mental illness & 1 & 1 & 5 & 0.000 \\
\hline $\begin{array}{l}\text { Long term conditions (Arthritis, Asthma, heart } \\
\text { disease, Alzheimer's disease) }\end{array}$ & 11 & 8 & 48 & 0.000 \\
\hline
\end{tabular}


Table 4: Results - The effect of chronic pain on life satisfaction - Overall sample

\begin{tabular}{|c|c|c|c|c|c|c|}
\hline & \multirow[b]{2}{*}{$\begin{array}{c}\text { OLS } \\
\text { Model } 1 \\
\end{array}$} & \multirow[b]{2}{*}{$\begin{array}{c}\text { OLS } \\
\text { Model } 2 \\
\end{array}$} & \multirow[b]{2}{*}{$\begin{array}{c}\text { OLS } \\
\text { Model } 3 \\
\end{array}$} & \multirow[b]{2}{*}{$\begin{array}{c}\text { ORDERED LOGIT } \\
\text { Model } 3 \\
\end{array}$} & \multicolumn{2}{|c|}{ Model 3} \\
\hline & & & & & $\begin{array}{l}\text { OLS RANDOM } \\
\text { EFFECTS }\end{array}$ & $\begin{array}{l}\text { OLS FIXED } \\
\text { EFFECTS }\end{array}$ \\
\hline Chronic pain & $\begin{array}{l}-0.781 \\
(0.019) * *\end{array}$ & $\begin{array}{l}-0.342 \\
(0.023) * *\end{array}$ & $\begin{array}{l}-0.309 \\
(0.023) * *\end{array}$ & $\begin{array}{l}-0.407 \\
(0.031)^{* *}\end{array}$ & $\begin{array}{l}-0.161 \\
(0.019) * *\end{array}$ & $\begin{array}{l}-0.090 \\
(0.021) * *\end{array}$ \\
\hline Log household income & $\begin{array}{l}0.080 \\
(0.006) * *\end{array}$ & $\begin{array}{l}0.041 \\
(0.006) * *\end{array}$ & $\begin{array}{l}0.094 \\
(0.007)^{* *}\end{array}$ & $\begin{array}{l}0.110 \\
(0.009)^{* *}\end{array}$ & $\begin{array}{l}0.026 \\
(0.007) * *\end{array}$ & $0.039(0.009) * *$ \\
\hline Control for Health status & No & Yes & Yes & Yes & Yes & Yes \\
\hline Control for Age & No & No & Yes & Yes & Yes & No \\
\hline $\begin{array}{l}\text { Control for Employment, } \\
\text { Marital Status and other } \\
\text { factors }\end{array}$ & No & No & Yes & Yes & Yes & Yes \\
\hline N. Observations & 102,520 & 102,520 & 90,142 & 90,142 & 90,142 & 90,142 \\
\hline R squared & 0.0189 & 0.0512 & 0.0994 & 0.0275 & 0.0897 & 0.0551 \\
\hline Adjusted R squared & 0.0188 & 0.0511 & 0.0991 & n.a. & n.a. & n.a. \\
\hline Within R squared & n.a & n.a & n.a & n.a & 0.017 & 0.0222 \\
\hline Between R squared & n.a & n.a & n.a & n.a & 0.1243 & 0.0679 \\
\hline
\end{tabular}

Note: Standard errors are in brackets + indicates that the underlying coefficient is significant at $10 \%$ level, * at $5 \%$ and $* *$ at $1 \%$. Pseudo R squared is reported for Ordered Probit model. 
Table 5: Results - The effect of chronic pain on life satisfaction - By gender

\begin{tabular}{|c|c|c|c|c|c|c|c|c|c|c|c|c|}
\hline & \multicolumn{6}{|c|}{ Men } & & \multicolumn{5}{|c|}{ Women } \\
\hline & & & & & Mod & lel 3 & & & & & Mod & el 3 \\
\hline & $\begin{array}{c}\text { OLS } \\
\text { Model } 1\end{array}$ & $\begin{array}{c}\text { OLS } \\
\text { Model } 2\end{array}$ & $\begin{array}{c}\text { OLS } \\
\text { Model } 3\end{array}$ & $\begin{array}{l}\text { Ordered } \\
\text { Logit } \\
\text { Model } 3 \\
\end{array}$ & $\begin{array}{c}\text { OLS } \\
\text { RANDOM } \\
\text { EFFECTS }\end{array}$ & $\begin{array}{c}\text { OLS } \\
\text { FIXED } \\
\text { EFFECTS }\end{array}$ & $\begin{array}{c}\text { OLS } \\
\text { Model } 1\end{array}$ & $\begin{array}{c}\text { OLS } \\
\text { Model } 2\end{array}$ & $\begin{array}{c}\text { OLS } \\
\text { Model } 3\end{array}$ & $\begin{array}{l}\text { Ordered } \\
\text { Logit } \\
\text { Model } 3\end{array}$ & $\begin{array}{c}\text { OLS } \\
\text { RANDOM } \\
\text { EFFECTS }\end{array}$ & $\begin{array}{c}\text { OLS } \\
\text { FIXED } \\
\text { EFFECTS }\end{array}$ \\
\hline Chronic pain & $\begin{array}{c}-0.769 \\
(0.029)^{* *}\end{array}$ & $\begin{array}{c}-0.341 \\
(0.034)^{* *}\end{array}$ & $\begin{array}{c}-0.330 \\
(0.034)^{* *}\end{array}$ & $\begin{array}{c}-0.432 \\
(0.047)^{* *}\end{array}$ & $\begin{array}{c}0.166 \\
(0.029)^{* *}\end{array}$ & $\begin{array}{c}-0.103 \\
(0.030) * *\end{array}$ & $\begin{array}{c}-0.797 \\
(0.256)^{* *}\end{array}$ & $\begin{array}{c}-0.348 \\
(0.030)^{* *}\end{array}$ & $\begin{array}{c}-0.298 \\
(0.031)^{* *}\end{array}$ & $\begin{array}{c}-0.396 \\
(0.042)^{* *}\end{array}$ & $\begin{array}{c}-0.157 \\
(0.027)^{* *}\end{array}$ & $\begin{array}{c}-0.077 \\
(0.028) * *\end{array}$ \\
\hline $\begin{array}{l}\text { Log } \\
\text { household } \\
\text { income }\end{array}$ & $\begin{array}{c}0.110 \\
(0.009)^{* *}\end{array}$ & $\begin{array}{c}0.069 \\
(0.009)^{* *}\end{array}$ & $\begin{array}{c}0.103 \\
(0.009)^{* *}\end{array}$ & $\begin{array}{c}0.124 \\
(0.014)^{* *}\end{array}$ & $\begin{array}{c}0.033 \\
(0.010)^{* *}\end{array}$ & $\begin{array}{c}0.038 \\
(0.013) * *\end{array}$ & $\begin{array}{c}0.063 \\
(0.008)^{* *}\end{array}$ & $\begin{array}{c}0.026 \\
(0.008)^{* *}\end{array}$ & $\begin{array}{c}0.086 \\
(0.010)^{* *}\end{array}$ & $\begin{array}{c}0.104 \\
(0.013)^{* *}\end{array}$ & $\begin{array}{c}0.022 \\
(0.010)^{* *}\end{array}$ & $\begin{array}{c}0.041 \\
(0.012) * *\end{array}$ \\
\hline $\begin{array}{l}\text { Control for } \\
\text { Health status }\end{array}$ & No & Yes & Yes & Yes & Yes & Yes & No & Yes & Yes & Yes & Yes & Yes \\
\hline $\begin{array}{l}\text { Control for } \\
\text { Age }\end{array}$ & No & No & Yes & Yes & Yes & No & No & No & Yes & Yes & Yes & No \\
\hline $\begin{array}{l}\text { Control for } \\
\text { Employment, } \\
\text { Marital } \\
\text { Status and } \\
\text { other factors }\end{array}$ & No & No & Yes & Yes & Yes & Yes & No & No & Yes & Yes & Yes & Yes \\
\hline $\begin{array}{l}\text { N. } \\
\text { Observations }\end{array}$ & 48,441 & 48,441 & 42,177 & 42,177 & 42,177 & 42,177 & 54,079 & 54,079 & 47,965 & 47,965 & 47,965 & 47,965 \\
\hline $\mathrm{R}$ squared & 0.0185 & 0.0482 & 0.0570 & 0.0238 & 0.0746 & 0.0451 & 0.0201 & 0.0558 & 0.1098 & 0.0311 & 0.1023 & 0.0676 \\
\hline $\begin{array}{l}\text { Adjusted R } \\
\text { squared }\end{array}$ & 0.0185 & 0.0478 & 0.0566 & n.a. & n.a. & n.a. & 0.0201 & 0.0554 & 0.1091 & n.a. & n.a. & n.a. \\
\hline $\begin{array}{l}\text { Within R } \\
\text { squared }\end{array}$ & n.a & n.a & n.a & n.a & 0.0158 & 0.0202 & n.a & n.a & n.a & n.a & 0.0195 & 0.0257 \\
\hline $\begin{array}{l}\text { Between R } \\
\text { squared }\end{array}$ & n.a & n.a & n.a & n.a & 0.1055 & 0.0584 & n.a & n.a & n.a & n.a & 0.1432 & 0.0838 \\
\hline
\end{tabular}

Note: Standard errors are in brackets + indicates that the underlying coefficient is significant at 10\% level, * at 5\% and **at 1\%. Pseudo R squared is reported for Ordered Probit model. 
Table 6: Results - Fixed effects estimation - Other variables (Model 3)

\begin{tabular}{|c|c|c|c|}
\hline Independent variables & $\begin{array}{c}\text { All } \\
\text { Sample } \\
\end{array}$ & Women & Men \\
\hline Education - Certificate or Diploma & $\begin{array}{r}-0.043 \\
(0.046)\end{array}$ & $\begin{array}{r}-0.054 \\
(0.061)\end{array}$ & $\begin{array}{r}-0.010 \\
(0.071)\end{array}$ \\
\hline $\begin{array}{l}\text { Education - High school or lower } \\
\text { qualification }\end{array}$ & $\begin{array}{r}0.045 \\
(0.042)\end{array}$ & $\begin{array}{r}0.023 \\
(0.054)\end{array}$ & $\begin{array}{r}0.095 \\
(0.066)\end{array}$ \\
\hline \multicolumn{4}{|l|}{ Health Conditions } \\
\hline Sight & $\begin{array}{r}0.032 \\
(0.030)\end{array}$ & $\begin{array}{r}-0.016 \\
(0.043)\end{array}$ & $\begin{array}{c}0.077 \\
(0.040)+\end{array}$ \\
\hline Hearing & $\begin{array}{r}-0.019 \\
(0.025)\end{array}$ & $\begin{array}{r}-0.044 \\
(0.042)\end{array}$ & $\begin{array}{r}-0.005 \\
(0.031)\end{array}$ \\
\hline Speech & $\begin{array}{l}-0.106 \\
(0.078)\end{array}$ & $\begin{array}{r}-0.063 \\
(0.122)\end{array}$ & $\begin{array}{r}-0.147 \\
(0.101)\end{array}$ \\
\hline Loss of consciousness & $\begin{array}{l}-0.222 \\
(0.056) * *\end{array}$ & $\begin{array}{l}-0.155 \\
(0.074)^{*}\end{array}$ & $\begin{array}{l}-0.332 \\
(0.086)^{* *}\end{array}$ \\
\hline Difficulties understanding & $\begin{array}{l}-0.084 \\
(0.048)+\end{array}$ & $\begin{array}{r}-0.085 \\
(0.073)\end{array}$ & $\begin{array}{r}-0.081 \\
(0.062)\end{array}$ \\
\hline Problem with arms & $\begin{array}{l}-0.046 \\
(0.030)\end{array}$ & $\begin{array}{r}-0.015 \\
(0.040)\end{array}$ & $\begin{array}{l}-0.082 \\
(0.044)+\end{array}$ \\
\hline Difficulties gripping things & $\begin{array}{r}-0.024 \\
(0.031)\end{array}$ & $\begin{array}{r}-0.029 \\
(0.040)\end{array}$ & $\begin{array}{r}-0.017 \\
(0.050)\end{array}$ \\
\hline Problem with legs & $\begin{array}{l}-0.068 \\
(0.024)^{* *}\end{array}$ & $\begin{array}{l}-0.066 \\
(0.033)^{*}\end{array}$ & $\begin{array}{l}-0.074 \\
(0.034)^{*}\end{array}$ \\
\hline Nervous or emotional condition & $\begin{array}{l}-0.401 \\
(0.028)^{* *}\end{array}$ & $\begin{array}{l}-0.445 \\
(0.036)^{* *}\end{array}$ & $\begin{array}{l}-0.333 \\
(0.044) * *\end{array}$ \\
\hline Condition that restricts physical activity & $\begin{array}{l}-0.057 \\
(0.017)^{* *}\end{array}$ & $\begin{array}{l}-0.090 \\
(0.024) * *\end{array}$ & $\begin{array}{l}-0.016 \\
(0.024)\end{array}$ \\
\hline Disfigurement or deformity & $\begin{array}{c}0.129 \\
(0.061)^{*}\end{array}$ & $\begin{array}{c}0.208 \\
(0.091)^{*}\end{array}$ & $\begin{array}{r}0.053 \\
(0.082)\end{array}$ \\
\hline Mental health condition & $\begin{array}{c}-0.320 \\
(0.043) * *\end{array}$ & $\begin{array}{c}-0.410 \\
(0.061)^{* *}\end{array}$ & $\begin{array}{c}-0.212 \\
(0.062)^{* *}\end{array}$ \\
\hline Difficulties breathing & $\begin{array}{c}-0.022 \\
(0.027)\end{array}$ & $\begin{array}{r}-0.002 \\
(0.036)\end{array}$ & $\begin{array}{l}-0.046 \\
(0.040)\end{array}$ \\
\hline Effects of head injury & $\begin{array}{c}-0.155 \\
(0.053)^{* *}\end{array}$ & $\begin{array}{r}-0.060 \\
(0.079)\end{array}$ & $\begin{array}{c}-0.234 \\
(0.071)^{* *}\end{array}$ \\
\hline Restrictive condition (despite being treated) & $\begin{array}{c}-0.084 \\
(0.018)^{* *}\end{array}$ & $\begin{array}{c}-0.085 \\
(0.025)^{* *}\end{array}$ & $\begin{array}{c}-0.081 \\
(0.026)^{* *}\end{array}$ \\
\hline Other condition & $\begin{array}{r}-0.017 \\
(0.016)\end{array}$ & $\begin{array}{r}-0.002 \\
(0.022)\end{array}$ & $\begin{array}{l}-0.034 \\
(0.023)\end{array}$ \\
\hline Rent & $\begin{array}{l}-0.067 \\
(0.016)^{* *}\end{array}$ & $\begin{array}{c}-0.063 \\
(0.023)^{* *}\end{array}$ & $\begin{array}{c}-0.070 \\
(0.023)^{* *}\end{array}$ \\
\hline Other housing & $\begin{array}{r}-0.030 \\
(0.031)\end{array}$ & $\begin{array}{r}-0.033 \\
(0.043)\end{array}$ & $\begin{array}{r}-0.026 \\
(0.045)\end{array}$ \\
\hline Unemployed & $\begin{array}{c}-0.159 \\
(0.024)^{* *}\end{array}$ & $\begin{array}{c}-0.132 \\
(0.034)^{* *}\end{array}$ & $\begin{array}{c}-0.188 \\
(0.034)^{* *}\end{array}$ \\
\hline Out of the labour force & $\begin{array}{c}0.001 \\
(0.015)\end{array}$ & $\begin{array}{c}0.036 \\
(0.019)+\end{array}$ & $\begin{array}{l}-0.048 \\
(0.024)^{*}\end{array}$ \\
\hline Separated & $\begin{array}{c}-0.467 \\
(0.030)^{* *}\end{array}$ & $\begin{array}{c}-0.421 \\
(0.041)^{* *}\end{array}$ & $\begin{array}{c}-0.505 \\
(0.044)^{* *}\end{array}$ \\
\hline
\end{tabular}


Widow

Single

Has children between 0 and 4

Has children between 5 and 9

Has children between 10 and 14

Inner regional area

Outer regional area (incl. remote)

Life events in the past 12 months

Personal illness or injury

Victim of violence

Other events

Constant

Observations

R squared

Within R squared

Between R squared
-0.429
$(0.049)^{*}$

$-0.225$

$(0.024)^{* * *}$

$-0.044$

$(0.017)^{* *}$

0.010

(0.016)

0.028

$(0.015)+$

0.103

$(0.026) * *$

$-0.019$

(0.035)

$-0.160$

$(0.014)^{* *}$

$-0.306$

$(0.032)^{* * *}$

$-0.033$

$(0.008)^{* * *}$

7.789

$(0.104)^{* *}$

90,142

0.0551

0.0222

0.0679
$-0.382$

$(0.059)^{* *}$

$-0.273$

$(0.034)^{* *}$

$-0.111$

$(0.024) * *$

0.007

(0.022)

$-0.018$

(0.020)

0.109

$(0.036) * *$

$-0.027$

(0.050)

$-0.193$

$(0.021)^{* *}$

$-0.358$

$(0.047) * *$

$-0.037$

$(0.012) * *$

7.857

$(0.143)^{* *}$

47,965

0.0676

0.0257

0.0838
$-0.513$

$(0.093) * *$

$-0.155$

$(0.035)^{* *}$

0.027

(0.024)

0.007

$(0.023)$

0.083

$(0.021)^{* *}$

0.096

$(0.036)^{* * *}$

$-0.009$

(0.049)

$-0.124$

$(0.020)^{* * *}$

$-0.247$

$(0.045)^{* * *}$

$-0.028$

$(0.012)^{*}$

7.675

$(0.151)^{* *}$

42,177

0.0451

0.0202 0.0584

Note: Standard errors are in brackets + indicates that the underlying coefficient is significant at $10 \%$ level, * at 5\% and **at $1 \%$. 
Table 7 - Adaptation and chronic pain (estimation with Model 3 - Fixed effects)

\begin{tabular}{|c|c|c|c|c|c|c|}
\hline & All sample & & Women & & Men & \\
\hline Pain $t$ & $\begin{array}{c}-0.094 \\
(0.020) * *\end{array}$ & $\begin{array}{c}-0.143 \\
(0.022) * *\end{array}$ & $\begin{array}{c}-0.078 \\
(0.028) * *\end{array}$ & $\begin{array}{c}-0.133 \\
(0.034) * *\end{array}$ & $\begin{array}{c}-0.113 \\
(0.031) * *\end{array}$ & $\begin{array}{c}-0.151 \\
(0.036) * *\end{array}$ \\
\hline $\begin{array}{l}\text { Past chronic pain (from } \mathrm{t}-1 \\
\text { to } \mathrm{t}-3 \text { ) }\end{array}$ & $\begin{array}{c}-0.078 \\
(0.037) * *\end{array}$ & $\begin{array}{c}-0.195 \\
(0.049) * *\end{array}$ & $\begin{array}{l}-0.019 \\
(0.050)\end{array}$ & $\begin{array}{c}-0.152 \\
(0.067) * *\end{array}$ & $\begin{array}{c}-0.162 \\
(0.056) * *\end{array}$ & $\begin{array}{c}-0.250 \\
(0.072) * *\end{array}$ \\
\hline $\begin{array}{l}\text { Pain } t * \text { Past chronic pain } \\
\text { (from t-1 to t-3) } \\
\text { Log Household Income }\end{array}$ & $\begin{array}{c}0.039 \\
(0.008)^{* *}\end{array}$ & $\begin{array}{c}0.229 \\
(0.063) * \\
0.039 \\
(0.008) * *\end{array}$ & $\begin{array}{c}0.041 \\
(0.012)^{* *}\end{array}$ & $\begin{array}{c}0.253 \\
(0.085) * \\
0.041 \\
(0.012)^{* *}\end{array}$ & $\begin{array}{c}0.038 \\
(0.013) * *\end{array}$ & $\begin{array}{c}0.181 \\
(0.095)+ \\
0.038 \\
(0.013) * *\end{array}$ \\
\hline $\begin{array}{l}\text { R squared } \\
\text { Within R squared } \\
\text { Between R squared }\end{array}$ & $\begin{array}{l}0.0566 \\
0.0223 \\
0.0696\end{array}$ & $\begin{array}{l}0.0570 \\
0.0224 \\
0.0704\end{array}$ & $\begin{array}{l}0.0680 \\
0.0257 \\
0.0842\end{array}$ & $\begin{array}{l}0.0685 \\
0.0259 \\
0.0852\end{array}$ & $\begin{array}{l}0.0478 \\
0.0205 \\
0.0618\end{array}$ & $\begin{array}{l}0.0482 \\
0.0206 \\
0.0624\end{array}$ \\
\hline
\end{tabular}

Note: Standard errors are in brackets + indicates that the underlying coefficient is significant at $10 \%$ level, $*$ at $5 \%$ and **at $1 \%$. Other independent variables are listed in Table 1.

Table 8 - Effect of duration of chronic pain (estimation with Model 3 - Fixed effects)

\begin{tabular}{lccc} 
& All sample & Women & Men \\
\hline $\begin{array}{l}\text { Years of chronic pain in the } \\
\text { survey }\end{array}$ & $\begin{array}{c}-0.066 \\
(0.020)^{* *}\end{array}$ & $\begin{array}{c}-0.048 \\
(0.027)+\end{array}$ & -0.091 \\
& & $0.031)^{*}$ \\
Years of chronic pain in the & 0.013 & 0.010 & 0.017 \\
survey squared & $(0.003)^{* *}$ & $(0.004)^{*}$ & $(0.005)^{*}$ \\
R squared & 0.0553 & 0.0703 & 0.0451 \\
Within R squared & 0.0378 & 0.0400 & 0.0457 \\
Between R squared & 0.0658 & 0.0841 & 0.0491 \\
\hline
\end{tabular}

Note: Standard errors are in brackets + indicates that the underlying coefficient is significant at $10 \%$ level, * at $5 \%$ and $* *$ at $1 \%$. Other independent variables are listed in Table 1. 


\section{References}

Access Economics (2007). The high price of pain: the economic impact of persistent pain in Australia. Report by Access Economics for the MBF Foundation.

Almond, D. (2006). Is the 1918 influenza pandemic over? Long term effects of in utero influenza exposure in the post 1940s US. Journal of Political Economy, 114, 672-712.

Ardelt, M. (1997). Wisdom and life satisfaction in old age. Journal of Gerontology, 52, 15-27.

Blanchflower, D.G., Oswald, A.J., (2008). Is well-being U-shaped over the life cycle? Social Science \& Medicine, 66, 1733-1749.

Carroll, N., Frijters, P., Shields, M. (2009). Quantifying the costs of drought: new evidence from life satisfaction data. Journal of Population Economics, 22, 445-461.

Cawley, J, Meyerhoefer, C. (2012). The medical care costs of obesity: an instrumental variables approach. Journal of Health Economics, 31, 219-30.

Chamberlain, G. (1980). Analysis of covariance with qualitative data. Review of Economic Studies, 47, 225-38.

Clark, A., Etile, F., Postel-Vinay, F., Senik, C., der Straeten, K. V., (2005). Heterogeneity in reported well-being: Evidence from twelve European countries. Economic Journal, 115, 118-132.

Clark, A., Georgellis, Y, Sanfey, P. (2001). Scarring: the psychological impact of past unemployment. Economica, 68, 221-241.

Clark, A., Oswald, A. (1994). Unhappiness and unemployment. Economic Journal, 104, 648-659.

Clark A., Oswald A. (2002). A simple statistical method for measuring how life events affect happiness. International Journal of Epidemiology, 31, 1139-1144.

Christensen, J., Bilde, L., Gustavsson, A. (2011). Socio-economic consequences of pain intensive diseases in Denmark. Danish Institute for Health Service Research.

Chuck, A. Jacobs, P., Ohinmaa, A., Dick, B., Rashiq, S. (2009). The Willingness to Pay for Reducing Pain and Pain-Related Disability. Value in Health, 12, 498-506.

Cobb-Clark, D.A., Schurer, S. (2012). The stability of Big Five personality traits. Economics Letters, 115, 11-15.

Debono, DJ; Hoeksema, LJ; Hobbs, RD (2013). Caring for Patients with Chronic Pain: Pearls and Pitfalls. Journal of the American Osteopathic Association, 113, 620-627

Dee, T. (1999). The complementarity of teen smoking and drinking. Journal of Health Economics $18,769-793$.

Diener E, Suh E. (1997). Measuring quality of life: economic, social and subjective indicators. Social Indicators Research, 40, 189-216.

Easterlin, R.A. (2005). A puzzle for adaptive theory. Journal of Economic Behavior and Organization, 56, 513-521.

Ferrer-I-Carbonell, A., van Praag, BMS. (2002). The subjective costs of health losses due to chronic diseases. An alternative model for monetary appraisal. Health Economics, 11, 709-722.

Ferrer-I-Carbonell, A. and Frijters, P. (2004). How important is the methodology for the determinants of happiness? Economic Journal, 114, 641-59.

Frey, B., Stutzer, A. (2000). Happiness, economy and institutions. Economic Journal 110: 918-938. 
Frijters, P., Haisken DeNew, J., Shields, M. (2004). Investigating the patterns and determinants of life satisfaction in Germany following reunification. The Journal of Human Resources, 39, 649-674.

Frot, M., Feine, J.S., Bushnell, M.C. (2004). Sex differences in pain perception and anxiety. A pychophysical study with topical capsaicin. Pain, 108, 230-236.

Galenkamp, H., Deeg, D.J., Braam, A.W., Huisman, M. (2012). How was your health 3 years ago? Predicting mortality in older adults using a retrospective change measure of self-rated health. Geriatric \& Gerontology International, 22, DOI.

Green, F. (2011). Unpacking the misery multiplier: How employability modifies the impacts of unemployment and job insecurity on life satisfaction and mental health. Journal of Health Economics, 30, 265-276.

Groot, W., Massen van den Brink, HM. (2004). A direct method for estimating the compensating income variation for severe headache and migraine. Social Science and Medicine, 58, 305314.

Groot, W., Massen van den Brink, HM. (2006). The compensating income variation of cardiovascular disease. Health Economics, 15, 1143-1148.

Groot, W., Massen van den brink, HM., Van Praag, B. (2007). The compensating income variation of social capital. Social Indicator Research, 82, 189-2007.

Hasmi J., Davis K. (2009). Women experience greater heat pain adaptation and habituation than men. Pain, 145, 350-357.

Heckman, J.J. (1979). Sample selection bias as a specification error. Econometrica, 47, 153-161.

Institute of Medicine of the National Academies. (2011). Relieving pain in America. National Academies Press: Washington DC.

Kapteyn, A., Smith, J. P., van Soest, A., (2008). Dynamics of work disability and pain. Journal of Health Economics, 27, 496-509.

Labelle, R., Hurley, J. (1992). Implications of basing health-care resource allocations on cost-utility analysis in the presence of externalities. Journal of Health Economics, 11, 259-277.

Martin, D., Schofield P., Jones, D., McNamee, P., Clarke, A., Anthony, B., Smith BH. (2013). The effect of Stanford-type self-management programmes on pain and function in older people with persistent pain: a systematic review of randomised controlled trials. Journal of Pain Management, 6, 117-122.

Mathew, R., Gucciardi, E., De Melo, M., Barata P. (2012). Self-management experiences among men and women with type 2 diabetes mellitus: a qualitative analysis. BMC Family Practice, 13, 11-12.

Mentzakis E, McNamee P, Ryan, M, Sutton, M. (2012). Valuing informal care experience: does choice of measure matter? Social Indicators Research, 108, 169-184.

Merskey H., Bogduk N.1994. (eds.) Classifications of chronic pain. Description of chronic pain syndromes and definition of pain terms, Ias Press: Seattle

Murray, M. (2006). Avoiding invalid instruments and coping with weak instruments. Journal of Economic Perspectives, 20, 111-132.

Oswald, A., Powdthavee, N. (2008). Does happiness adapt? A longitudinal study of disability with implications for economists and judges. Journal of Public Economics, 92, 1061-1077. 
Powdthavee, N. (2005). Unhappiness and Crime: Evidence from South Africa. Economica,72, 531547.

Pfitzer Australia , (2011). Pfitzer Health Report. Chronic pain. Pfitzer Australia

Philips, C., (2009). The cost and burden of chronic pain. Reviews in Pain, 3, 2-5.

Philips, C., Harper, C. (2011). The economics associated with persistent pain. Current Opinion in Supportive and Palliative Care, 5, 127-130.

Rees, D., Saabia, J. (2011). The effect oif migraine headache on educational attainment. Journal of Human Resources 46, 317-332

Schofield, D.J., Callander, E.J., Shrestha, R.N., Passey, M.E., Percival, R., Kelly, S.J. (2012). Association between co-morbidities and labour force participation amongst persons with back problems. Pain, 153, 2068-2072.

Stewart, W.F., Ricci, J.A., Chee, E., et al. (2003). Lost productive time and cost due to common pain conditions in the US workforce. Journal of the American Medical Association, 18, 2443-2454.

Van Praag, B., Ferrer-I-Carbonell, A., (2004). Happiness Quantified: A Satisfaction Calculus Approach. Oxford University Press, Oxford.

Veenhoven, R. (2007). Subjective measures of well-being, in McGillivray M (ed.), Human Wellbeing: Concept and Measurement. Houndmills, New Hampshire: Palgrave/McMillan, 214239.

Winkelmann, L, Winkelmann, R. (1998). Why are the unemployed so unhappy? Evidence from panel data. Economica, 65, 1-17.

Winkelmann, R. (2005). Subjective well-being and the family: Results from an ordered probit with multiple random effects. Empirical Economics, 30, 749-761.

Wooden, M., Watson, N., (2002). The Household, Income and Labour Dynamics in Australia (HILDA) survey: An introduction. Australian Social Policy 2001-02, 79-100.

Wooden, M., Warren, D., Drago, R., (2009). Working time mismatch and subjective well-being. British Journal of Industrial Relations, 47, 147-179.

Wooldridge, J. (2002). Econometric analysis of cross sections and panel data, MIT press, Cambridge, Massachussets. 